\title{
A nova lei brasileira sobre o livro, a leitura, a escrita, a literatura e as bibliotecas públicas
}

\author{
Murilo Bastos da Cunha \\ Universidade de Brasília, Faculdade de Ciência da Informação, Brasília, DF, Brasil \\ murilobc@unb.br
}

DOI: https://doi.org/10.26512/rici.v11.n3.2018.10532

Recebido/Recibido/Received: 2018-07 05

Aceitado/Aceptado/Accepted: 2018-07-27

Resumo: O editorial comenta a lei brasileira n. 13.696, de 12 de julho de 2018, que institui a Política Nacional de Leitura e Escrita, como estratégia de promoção do livro, da leitura, da escrita, da literatura e das bibliotecas públicas no Brasil. Além disso, são comentados os artigos incluídos no terceiro número de 2018 da Revista Ibero-Americana de Ciência da Informação.

Palavras-chave: Bibliotecas públicas. Brasil. Leitura. Políticas públicas.

The new Brazilian law on books, reading, writing, literature and public libraries Abstract: The editorial comments on the Brazilian law n. 13,696 of July 12, 2018, which establishes the National Politics of Reading and Writing, as a strategy for the promotion of books, reading, writing, literature and public libraries in Brazil. In addition, the articles included in the third issue of 2018 of the Ibero-American Journal of Information Science are commented on.

Keywords: Brazil. Public libraries. Public policy. Reading.

La nueva ley brasileña sobre el libro, la lectura, la escritura, la literatura y las bibliotecas públicas Resumen: El editorial comenta la ley brasileña n. 13.696, de 12 de julio de 2018, que instituye la Política Nacional de Lectura y Escritura, como estrategia de promoción del libro, de la lectura, de la escritura, de la literatura y de las bibliotecas públicas en Brasil. Además, se comentan los artículos incluidos en el tercer número de 2018 de la Revista Iberoamericana de Ciencia de la Información.

Palabras-clave: Bibliotecas públicas. Brasil. La lectura. Políticas públicas.

Caro Leitor,

Nos tempos atuais há algo positivo a ser comemorado: passou pela sanção presidencial, em 12 de julho de 2018, a lei n. 13.696 (BRASIL. Lei n. 13.696), que institui a Política Nacional de Leitura e Escrita (PNLE), como estratégia de promoção do livro, da leitura, da escrita, da literatura e das bibliotecas públicas no Brasil.

A proposta inicial do projeto de lei remonta à uma sugestão do conselho do Plano Nacional do Livro e Leitura (PNLL), presidido, à época, por José Castilho Marques Neto. A proposta buscou fortalecer o Sistema Nacional de Bibliotecas Públicas (SNBP), no âmbito do 
Sistema Nacional de Cultura (SNC), promovendo ainda as demais políticas de estímulo à leitura, ao conhecimento, às tecnologias e ao desenvolvimento educacional, cultural e social do país. A proposta foi apresentada em 2016, à senadora Fátima Bezerra (PT/RN), autora do projeto do qual se originou a lei (POLÍTICA, 2017). A nova norma legal também é conhecida como "Lei Castilho", por ter sido apresentada por José Castilho Marques Neto (SINDICATO NACIONAL DOS EDITORES DE LIVROS).

A implementação do PNLE cabe à União, por intermédio dos ministérios da Cultura e da Educação, em cooperação com os Estados, Municípios e Distrito Federal e com participação da sociedade civil e instituições privadas. Para isso, a PNLE prevê a elaboração, a cada 10 anos, do Plano Nacional do Livro e da Leitura (PNLL), com metas e ações, pelos ministérios da Cultura e Educação em diálogo com o Conselho Nacional de Política Cultural (CNPC), o Conselho Nacional de Educação (CNE), representantes de secretarias estaduais e municipais de cultura e educação, como também da sociedade civil.

No art. 3ํ da lei são apontados os seus objetivos, a saber:

I - democratizar o acesso ao livro e aos diversos suportes à leitura por meio de bibliotecas de acesso público, entre outros espaços de incentivo à leitura, de forma a ampliar os acervos físicos e digitais e as condições de acessibilidade;

II - fomentar a formação de mediadores de leitura e fortalecer ações de estímulo à leitura, por meio da formação continuada em práticas de leitura para professores, bibliotecários e agentes de leitura, entre outros agentes educativos, culturais e sociais;

III - valorizar a leitura e o incremento de seu valor simbólico e institucional por meio de campanhas, premiações e eventos de difusão cultural do livro, da leitura, da literatura e das bibliotecas;

IV - desenvolver a economia do livro como estímulo à produção intelectual e ao fortalecimento da economia nacional, por meio de ações de incentivo ao mercado editorial e livreiro, às feiras de livros, aos eventos literários e à aquisição de acervos físicos e digitais para bibliotecas de acesso público;

$\mathrm{V}$ - promover a literatura, as humanidades e o fomento aos processos de criação, formação, pesquisa, difusão e intercâmbio literário e acadêmico em território nacional e no exterior, para autores e escritores, por meio de prêmios, intercâmbios e bolsas, entre outros mecanismos;

VI - fortalecer institucionalmente as bibliotecas de acesso público, com qualificação de espaços, acervos, mobiliários, equipamentos, programação cultural, atividades pedagógicas, extensão comunitária, incentivo à leitura, capacitação de pessoal, digitalização de acervos, empréstimos digitais, entre outras ações;

VII - incentivar pesquisas, estudos e o estabelecimento de indicadores relativos ao livro, à leitura, à escrita, à literatura e às bibliotecas, com vistas a fomentar a produção de conhecimento e de estatísticas como instrumentos de avaliação e qualificação das políticas públicas do setor;

VIII - promover a formação profissional no âmbito das cadeias criativa e produtiva do livro e mediadora da leitura, por meio de ações de qualificação e capacitação sistemáticas e contínuas;

IX - incentivar a criação e a implantação de planos estaduais, distrital e municipais do livro e da leitura, em fortalecimento ao SNC;

$X$ - incentivar a expansão das capacidades de criação cultural e de compreensão leitora, por meio do fortalecimento de ações educativas e culturais focadas no desenvolvimento das competências de produção e interpretação de textos. 
A nova norma legal, a Política Nacional de Leitura e Escrita (PNLE) respeitará os princípios e as diretrizes do Plano Nacional da Educação; do Plano Nacional de Cultura; e do Plano Plurianual da União (PPA). O artigo 2ำ da nova legislação (BRASIL. Lei n. 13.696), aponta que são diretrizes do PNLE:

I - a universalização do direito ao acesso ao livro, à leitura, à escrita, à literatura e às bibliotecas;

II - o reconhecimento da leitura e da escrita como um direito, a fim de possibilitar a todos, inclusive por meio de políticas de estímulo à leitura, as condições para exercer plenamente a cidadania, para viver uma vida digna e para contribuir com a construção de uma sociedade mais justa;

III - o fortalecimento do Sistema Nacional de Bibliotecas Públicas (SNBP), no âmbito do Sistema Nacional de Cultura (SNC);

IV - a articulação com as demais políticas de estímulo à leitura, ao conhecimento, às tecnologias e ao desenvolvimento educacional, cultural e social do País, especialmente com a Política Nacional do Livro, instituída pela Lei oㅜ 10.753, de 30 de outubro de 2003;

$\mathrm{V}$ - o reconhecimento das cadeias criativa, produtiva, distributiva e mediadora do livro, da leitura, da escrita, da literatura e das bibliotecas como integrantes fundamentais e dinamizadoras da economia criativa.

Agora, é preciso que os profissionais e as entidades bibliotecárias, culturais e educacionais acompanhem e pressionem para que, segundo o art. 6 da lei, não demore o "ato conjunto do Ministério da Cultura e do Ministério da Educação regulamentará o disposto nesta Lei" (BRASIL. Lei n. 13.696).

No terceiro número da RICl em 2018 foram selecionados para publicação onze artigos, um artigo de revisão de literatura e um documento.

Boa leitura e até o nosso próximo número!

\section{Referências}

BRASIL. Lei n. 13.696, de 12 de julho de 2018. Institui a Política Nacional de Leitura e Escrita. Disponível em: http://www.planalto.gov.br/ccivil 03/ ato2015-2018/2018/Lei/L13696.htm Acesso em: 16 julho 2018.

POLÍTICA Nacional de Leitura e Escrita (PNLE) é aprovada na Comissão de Educação. G1, 6 out. 2017. Disponível em: https://g1.globo.com/educacao/noticia/politica-nacional-de-leitura-eescrita-pnle-e-aprovada-na-comissao-de-educacao.ghtml Acesso em: 7 out. 2017.

SINDICATO NACIONAL DOS EDITORES DE LIVROS. Sancionada lei que institui a Política Nacional de Leitura e Escrita (PNLE). 14 jul. 2018. Disponível em: http://www.snel.org.br/sancionada-leique-institui-a-politica-nacional-de-leitura-e-escrita-pnle/ Acesso em: 16 jul. 2018. 